\section{PROJETO DA NOVA LEI DE LICITAÇÕES: UMA ANÁLISE DOS PRINCIPAIS AVANÇOS E CRÍTICAS}

\author{
NEW BIDDING LAW PROJECT: AN ANALYSIS OF THE \\ MAIN ADVANCES AND CRITICISMS
}

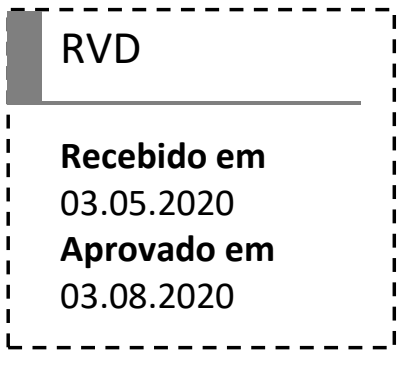

Lidiane Dutra Dias ${ }^{12}$

\title{
RESUMO
}

Este trabalho tem por objetivo examinar os principais avanços e críticas atribuídos ao Projeto da Nova Lei de Licitações que tramita no Congresso Nacional brasileiro com o escopo de conferir maior eficiência e de exaltar estratégias de combate à corrupção em licitações e contratos administrativos. Para tanto, necessário se fez proceder a uma investigação jurídica e teórica, através da técnica de documentação indireta por meio de pesquisa, para analisar detidamente alguns dos novos institutos inseridos no novo texto, com seus pontos positivos e negativos, bem como as melhorias acrescentadas às previsões já existentes no ordenamento jurídico. Ademais, foram apresentados os pontos em que o projeto do novo texto normativo é omisso e apresenta falhas.

Palavras-chave: Licitações. Contratos administrativos. Projeto de lei.

\begin{abstract}
This work pretend to examine the main advances and criticisms attributed to the New Bidding Law Project that is being processed in the Brazilian National Congress with the aim of providing greater efficiency and extolling strategies to fight corruption in public tenders and contracts. For this, it was necessary to carry out a legal and theoretical investigation, through the technique of indirect documentation through research, to thoroughly analyze some of the new institutes inserted in the new text, with their positive and negative points, as well as the improvements added to the forecasts already existing in the legal system. In addition, the points were presented where the design of the new normative text is omitted and has flaws.
\end{abstract}

Keywords: Bids. Administrative contracts. Bill.

\footnotetext{
${ }^{1}$ Graduada pela Universidade Federal de Juiz de Fora/MG - UFJF, * Especialista em Direito Público, Especialista em Direito Previdenciário, Especialista em Direito Processual Penal. EMAIL: lidiane dutradias@hotmail.com. ORCID: 0000-0002-5678-3046.

2 Endereço para correspondência: Rua Espírito Santo, nำ1290/303, Centro, Juiz de Fora/MG. CEP: 36016-200.
} 


\section{INTRODUÇÃO}

Após inúmeras reivindicações e críticas ao seu texto, a Lei 8.666/1993 caminha para revogação, o que se depreende dos importantes e avançados debates que são feitos no âmbito de projetos de lei em tramitação nas Casas Legislativas que objetivam o estabelecimento de uma nova lei geral em matéria de licitações e contratos.

Inobstante algumas leis terem introduzido relevantes alterações na redação original da Lei 8.666/1993 - tais como as Leis o 8.883/1994, ํo 9.648/1998, ํo 9.854/1999, ㄲo 12.349/2010, Lei Complementar ํo 147/2014, ํo 13.146/2015, ํo 13.465/2017 e outras -, a intenção de modificar substancialmente o sistema previsto na legislação vigente não se materializou.

A edição de leis esparsas incluiu no ordenamento nova visão no plano das contratações públicas, como por exemplo criando o pregão, através da Lei 10.520/2002, e o Regime Diferenciado de Contratação, com a publicação da Lei 12.462/2011, além de outros institutos que circundam o tema.

Com o escopo de discutir uma significativa reforma nas regras gerais de licitações e contratos, em 28 de maio de 2013, por ato do então Presidente do Senado Federal, Renan Calheiros, instituiu-se a Comissão Temporária de Modernização da Lei de Licitações e Contratos.

Naquela época, o escopo principal não era editar uma nova lei geral sobre o tema, mas apenas "debater e apresentar proposta de atualização e modernização da Lei n ${ }^{\circ} 8.666$, de 21 de junho de 1993".

Após o recebimento de cinquenta e seis emendas dos senadores, o Projeto de Lei 559, mediante relatório do Senador Fernando Bezerra, teve seu texto final aprovado em 13 de dezembro de 2016 na Casa Iniciadora, após o que seguiu para a Câmara dos Deputados.

Depois da longa tramitação no Senado Federal (dezembro de 2013 a dezembro de 2016), o PL foi recebido na Casa Revisora, onde foi autuado como PL no 6.814, em fevereiro de 2017. Cumprindo normas do Regimento Interno da Câmara dos 
Deputados, o Presidente desta Casa, Rodrigo Maia, determinou a criação de Comissão Especial para análise do projeto, o que de fato foi implementado em 27 de fevereiro de 2018, definindo como presidente da Comissão Especial o Deputado Augusto Coutinho e como Relator o Deputado João Arruda.

Observando-se a conexão entre as temáticas do PL em análise com o PL ํo 1.292/1995, o líder da minoria na Câmara, Deputado José Guimarães, requereu o apensamento deste último ao projeto em trâmite, o que foi deferido pela Mesa Diretora da Casa.

Inúmeras audiências públicas e oitivas de especialistas foram realizadas para incremento e melhoramento do que se propunha. Finalmente, em 05 de dezembro de 2018, o relatório do Deputado João Arruda foi apreciado e aprovado.

O novo texto que substituiu o do Senado Federal foi ao Plenário da Câmara dos Deputados em 08 de maio de 2019, oportunidade em que foram apresentadas cento e dezessete emendas, razão pela qual precisou ser ajustado, retornando a sessão plenária em 25 de junho de 2019, quando o texto-base foi aprovado pela Casa Revisora. Nos dias 10, 11 e 17 de setembro de 2019, foi aprovado o texto definitivo, encaminhado ao Senado Federal novamente, em razão das emendas, em 10 de outubro de 2019.

Até o fechamento deste trabalho, o projeto de lei substitutivo da Câmara, materializado no PL 1.292/95, não foi efetivamente recebido pela Casa Iniciadora. Isso porque ainda não foi discutido em Plenário, o que, segundo normas constantes do Regimento Interno do Senado Federal - RISF, deve ser feito artigo por artigo, por considerar que o substitutivo consiste em uma série de emendas ao texto original, votando-se os artigos, parágrafos, incisos e alíneas, separadamente.

Assim, quando da sessão plenária referida, o Senado aprovará ou rejeitará, total ou parcialmente, as emendas propostas na outra Casa, tal como prevê o rito do processo legislativo brasileiro.

Trouxemos um resumo abreviado do aspecto formal do projeto de lei que pretende trazer nova sistematização de licitações e contratos administrativos, segundo as informações colhidas no site do Observatório da Nova Lei de Licitações - ONLL, que 
reúne vários artigos científicos de pesquisadores que se debruçaram sobre o assunto (vide referências).

Pretende-se focar, nos capítulos posteriores, nos aspectos materiais do tema.

O PL consolida a maioria dos institutos afetos às contratações públicas, revogando as Leis 8.666/93, 10.520/02 e 12.462/11.

Assim, União, Estados e Municípios, em todos os seus poderes, estarão sujeitos às novas regras após a vacatio designada pela futura lei, caso venha a se concretizar, permanecendo mantidas, porém, no que couber, as regras relativas às concessões e permissões públicas - dentre as quais destaco as Leis №8.9871995 e ㄲ⒒079/2004.

Por certo, empresas estatais não estarão submetidas ao novo regime eis que, desde a publicação da Lei $13.303 / 16$, possuem normativa própria no tocante às licitações, exceto no que expressamente remeta à lei geral.

A inovação legislativa no sistema de contratações públicas traz inúmeros avanços que buscam facilitar o procedimento licitatório e o futuro contrato administrativo. Lado outro, algumas lacunas também podem ser observadas no projeto de lei aprovado pelas Casas Legislativas.

O desafio do presente trabalho é apurar em que medida o que se propõe avança e em que medida desperdiça a oportunidade para aperfeiçoar ainda mais o sistema, deixando lacunas.

O PL 6814/2017 e seu apenso PL1292/1995, como já mencionado, ainda não terminaram seus trâmites legislativos, razão pela qual não estão em vigor as novas regras.

Entretanto, é possível dizer que, com base nas modificações que o projeto de lei propõe, a nova normativa pautar-se-á em dois grandes vetores: o enfrentamento à ineficiência estatal e o combate à corrupção. Trata-se das maiores preocupações do legislador infraconstitucional no momento.

O modo como isso vem sendo proposto no novo texto legal é o que se busca demonstrar nos próximos tópicos, avaliando-se os avanços e as críticas que já vem sendo pontuadas acerca do PL. 
Para cumprir este mister, o presente trabalho se utilizará, precipuamente, da investigação jurídica, teórica e legal, em especial no tocante aos aspectos conceituais e doutrinários quanto ao objeto de estudo. Escolhida a técnica, qual seja a documentação indireta, por meio da pesquisa bibliográfica e legal, se selecionará livros, artigos científicos e leis.

\section{PREVENÇÃo À CORRUPÇÃo}

Quando surgiram as primeiras minutas do projeto de lei que ditaria novas regras para as contratações públicas, a preocupação com o enfrentamento à corrupção não estava em pauta, de maneira que sua original redação abria margens excessivas para práticas desleais de agentes públicos e particulares em colaboração com a Administração Pública.

Após sucessivos escândalos de corrupção especialmente na classe política e dentro das estatais brasileiras, a sociedade "acordou" para o nefasto problema que gera prejuízos financeiros incalculáveis para o Estado, o que repercute diretamente em decadência da educação, saúde, segurança, entre outros, dos administrados.

Ante este cenário, o combate à corrupção passou a ser assunto que necessariamente precisava ser inserido no âmbito da contratação pública, para dificultar a ação de corruptores em prejuízo do interesse e patrimônio públicos.

Considerando que ainda tramita o projeto de lei geral para licitação e contratos nas Casas Legislativas, não havia oportunidade melhor para inserir elementos e que, de fato, contribuiriam para minimizar o problema da corrupção, o que foi feito acrescentando-se paulatinamente novos institutos e artigos.

Trata-se, portanto, da criação de mecanismos e instrumentos aptos ao combate à corrupção.

Nos subitens a seguir, serão explanadas as abordagens trazidas, neste sentido, pelo projeto da Nova Lei de Licitações.

\section{1 - Programas de integridade}


Integridade consubstancia-se em atributo de algo ou alguém em virtude de sua atuação íntegra, proba, reta, honrada ou justa.

Com o escopo de assegurar que os contratantes com a Administração Pública ajam sempre de forma adequada às normas que the são impostas, afastando atitudes que não observam o fim último das licitações que é o interesse público, a nova legislação passa a premiar as empresas que investem em programas de integridade e compliance em algumas situações.

Segundo a inteligência da professora Mirela Miró Ziliotto:

[...] A intenção do legislador parece bastante clara ao utilizar os Programas de Integridade e Compliance como instrumento de autoconhecimento e aculturamento das empresas que contratam com o Poder Público para uma realidade da integridade, conformidade, ética e transparência. Assim, se o que move a sociedade são os valores nela inseridos, e a incorreção em determinada comunidade for aceitável, aqueles que a integram serão mais propensos à desonestidade e vice-versa. Nesses termos, da mesma forma que a presença de comportamento corrupto encoraja outros comportamentos corruptos, a diminuição do predomínio da corrupção pode enfraquecê-la ainda mais, de modo que a inversão de direção desse círculo vicioso implicará a existência de um círculo virtuoso (ZILIOTTO, 2019, [s.p.]).

Dessa forma, os licitantes passam a avaliar sua participação no certame público através do binômio investimentos necessários versus ganhos que eles esperam que dos programas defluam.

Isso porque, na maioria das situações, o programa de integridade não se apresenta como um requisito obrigatório, sendo, portanto, uma faculdade do licitante que lhe traz vantagem.

Exemplo disso é que tais providências da empresa consubstanciam novo critério de desempate entre as propostas apresentadas em uma licitação, tal como prevê o artigo 58 do PL; logo, aquele quem não tem os programas de integridade estão em desvantagem, apesar de, neste caso, não serem de implementação obrigatória.

Do mesmo modo, as sanções a serem aplicadas a pessoas jurídicas que comprovem ter implementado ou aperfeiçoado seus programas de integridade serão menos severas, de modo a atenuar sua punição perante o processo administrativo. É o que notamos no art.154 do projeto de lei. 
Há, porém, duas exceções constantes dos artigos 24 e 161. São cenários em que há obrigatoriedade de instituir os programas de integridade no âmbito da empresa. São elas: i) Quando da reabilitação da declaração de inidoneidade a pessoa jurídica terá que apresentar novo programa de integridade ou melhorias naquele já existente que apresenta falhas. Mas isso também só ocorrerá em dois casos, os quais estão expostos nos incisos VIII e XII do art.153 do PL: se o licitante ou contratado apresentar declaração ou documentação falsa exigida para o certame ou prestar declaração falsa durante a licitação ou a execução do contrato ou quando cometer algum dos atos lesivos à Administração Pública elencados no art.5ำ da Lei 12.846/2013; ii) Em caso de contratações de obras, serviços e fornecimento de grande vulto, que tem valor estimado de $R \$ 200.000 .000,00$ (duzentos milhões de reais), conforme prescrito no art. $6^{\circ}$, inciso XXII, do PL1292/95.

Assim, o incentivo aos programas de integridade, conferindo vantagens a empresas que os implementem ou aperfeiçoem, consubstancia-se em uma das formas que o legislador infraconstitucional encontrou de valorizar aquele que aja de forma íntegra, proba, buscando-se o combate à corrupção.

A iniciativa tem sido bem vista pelos críticos em geral, pois com ela espera-se afastar as nefastas trocas de favores e combinações espúrias que, como se sabe, assolam as contratações públicas e fere substancialmente a competitividade necessária ao atendimento do interesse público.

É preciso, no entanto, sejam pensadas melhorias para o projeto de lei neste ponto eis que, da forma como foi escrita, teme-se que as empresas licitantes implementem normas de integridade e compliance objetivando tão somente atender à exigência legal, sem controle de qualidade e eficiência, uma que vez não há previsão de como será feita essa verificação.

O ideal seria que a nova normativa já trouxesse em seu bojo critérios, fatores e métodos que facilitassem a apuração do atendimento das exigências de modo eficiente.

$\mathrm{Na}$ prática, alguns Estados já têm suas próprias leis que impõem a implementação de tais programas às empresas contratantes com a Administração Pública, como por exemplo, a Lei $7.753 / 17$ no Rio de Janeiro, a Lei $15.228 / 18$ no Rio 
Grande do Sul e a Lei $6.308 / 19$ no Distrito Federal, o que demonstra que a preocupação com a integridade de fornecedores e o combate à corrupção têm, paulatinamente, conquistado notório papel no País (ZILIOTTO, 2019, [s.p]).

\section{2 - Discricionariedade versus objetividade das sanções}

Hodiernamente, o modo como são estruturados os contratos administrativos é quase um assenhoramento do Poder Público quanto a suas cláusulas.

As prerrogativas públicas ditam a forma como deve agir o contratado segundo vontades preestabelecidas pela Administração, sempre tendo como finalidade remota a busca pelo alcance do interesse público, com o máximo de eficiência.

Para lograr êxito neste mister, pode o gestor público lançar mão de reprimendas que deverão ser aplicadas ao contratado omisso ou descumpridor das cláusulas. Neste ponto, entretanto, a Lei 8.666/93 sempre foi alvo de inúmeras críticas na maneira como tratou o tema. Isso porque aquele diploma legal, inobstante prolixo em outros momentos, detalhando por demasiado certos institutos, no tocante às sanções administrativas foi sucinto, trazendo a lume em apenas três artigos (do 86 ao 88) uma abordagem bastante superficial.

No artigo 87, por exemplo, não existe correspondência entre as sanções ali expostas e os casos em que são aplicadas cada uma delas.

Como se vê, este dispositivo expõe que poderão ser aplicadas as sanções de advertência, multa, suspensão temporária de participação em licitação ou impedimento de contratar com a Administração e declaração de idoneidade para licitar ou contratar com a Administração. No entanto, o legislador deixa à discricionariedade do gestor público decidir qual dessas reprimendas aplicará em cada caso, o que pode resultar em distorções e desproporções indesejáveis, tais como resultados diferenciados para faltas semelhantes.

Isso porque o legislador deixou para que cada ente preveja a sanção aplicável ao caso concreto: (i) em um decreto no seu âmbito territorial, (ii) em cada contrato administrativo que celebrar ou (iii) não preveja em lugar nenhum e, a cada falta, decida 
qual é, na sua avaliação, qual deve ser a reprimenda indicada para a situação em análise.

Ausente a objetividade que se espera da previsão de sanções, abre-se a possibilidade de uma má escolha pelo gestor, como por exemplo, a aplicação de uma medida desproporcional ao ato faltoso.

Mais reprovável que isso, não havendo precisão no parâmetro delineador da reprimenda é possível que se abra espaço para ações corruptivas, podendo o responsável pela aplicação da medida valer-se dessa discricionariedade aberta pelo legislador infraconstitucional para auferir vantagem indevida junto ao particular, prometendo-lhe o abrandamento da sanção.

Com a pretensão de enfrentamento à corrupção, o PL 6814/17 acaba por estabelecer uma correlação entre comportamento e a aplicação de cada sanção, chegando inclusive a prever situações que agravam e que atenuam a reprimenda. Tal previsão legislativa avança em relação ao modelo atualmente vigente porque traz mais objetividade, minimizando o poder discricionário do gestor público.

Observa-se que a redação do artigo 154 do PL traz uma maior sistematização do tema, apontando qual sanção se aplica a qual infração administrativa, o que confere maior justiça à escolha do gestor e extirpa - ou ao menos atenua - a ocorrência da corrupção.

É certo que a Lei do Pregão (Lei 10.520/02) previu algo parecido ao narrar algumas condutas e, logo na sequência, informar a reprimenda que deveria sofrer. Entretanto, podemos perceber que o legislador infraconstitucional redigiu de forma confusa 0 artigo $7^{\circ}$ deste diploma normativo, levantando uma série de dúvidas nos intérpretes e aplicadores do Direito.

Por exemplo, as condutas de não se apresentar para a celebração do contrato e de entregar documentos falsos à Administração são situações absurdamente diferentes do ponto de vista da justiça comportamental, mas que, à luz do disposto no artigo supramencionado, acabam por receber a mesma punição.

Dessa forma, mesmo que a Lei do Pregão já represente este avanço no plano da objetividade das sanções, ainda não o faz de modo exemplar. E, enfim, com a Nova Lei 
de Licitações teremos essa transparência, a nosso ver ideal, na aplicação das reprimendas.

\section{3 - Tipificações penais}

Como estratégia ao enfrentamento às ações desviantes da lei em matéria de licitações e contratos, mormente a corrupção, o PL №1.292/1995 endurece o tratamento penal aos crimes já previstos na Lei nำ.666/1993 além de incluir novos delitos, instituindo para tanto um novo capítulo ao próprio Código Penal no "Título XI - Dos Crimes Contra a Administração Pública", intitulado "Dos Crimes em Licitações e Contratos Administrativos".

Nos delitos que se assemelham em ambos os textos normativos, observa-se que em muitos a punição deixou de ser com detenção para sancionar o infrator com reclusão, além de ter o quantum de pena elevado.

Assim, a título de exemplo, o crime de contratação direta ilegal que no atual ordenamento jurídico (artigo 89 da Lei nำ.666/93) prescreve pena de detenção de 02 (dois) a 04 (quatro) anos, e multa, passa a ser mais severamente punido, sendo tipificado no Código Penal, artigo 337-E, com pena de reclusão, de 3 (três) a 5 (cinco) anos, e multa.

O mesmo se diga em relação aos delitos de frustração do caráter competitivo de licitação, patrocínio de contratação indevida, modificação ou pagamento irregular em contrato administrativo e perturbação de processo licitatório, afastamento de licitante, conforme se vê dos artigos 90 a 93 e 95 da Lei 8.666 e artigos 337-F a 337-I e 337-K.

Acerca do endurecimento de penas, entretanto, o crime que sofreu maior aumento da repressão penal foi o de fraude em licitação ou contrato, o que era de se esperar ante a tendência do legislador a tratar com mais rigor delitos ligados à corrupção. Vejamos a distinção de tratamento no sistema atual e no do projeto de lei: 
II - vendendo, como verdadeira ou perfeita, mercadoria falsificada ou deteriorada;

III - entregando uma mercadoria por outra;

IV - alterando substância, qualidade ou quantidade da mercadoria fornecida;

$\mathrm{V}$ - tornando, por qualquer modo, injustamente, mais onerosa a proposta ou a execução do contrato:

Pena - detenção, de 3 (três) a 6 (seis) anos, e multa.

\section{PL no1.292/1995:}

Art. 337-L. Fraudar, em prejuízo da Administração Pública, licitação ou contrato dela decorrente, com o intuito de obter, para si ou para outrem, vantagem indevida, mediante:

I - entrega de mercadoria ou prestação de serviços com qualidade ou em quantidade diversas das previstas no edital ou nos instrumentos contratuais;

II - fornecimento, como verdadeira ou perfeita, de mercadoria falsificada, deteriorada, inservível para consumo ou com prazo de validade vencido;

III - entrega de uma mercadoria por outra;

IV - alteração da substância, qualidade ou quantidade da mercadoria ou do serviço fornecido;

$\mathrm{V}$ - qualquer meio fraudulento que torne injustamente mais onerosa para a Administração Pública a proposta ou a execução do contrato.

Pena - reclusão, de 4 (quatro) anos a 8 (oito) anos, e multa.

Parágrafo único. A pena é de reclusão de 4 (quatro) a 12 (doze) anos, e multa, se houver sobrepreço ou superfaturamento. (grifos nossos)

Depreende-se daí que o legislador pretende elevar em muito o rigor da sanção penal neste delito, de modo que, por exemplo, no caso de o indivíduo inserir sobrepreço ou impor superfaturamento em cima da mercadoria ou serviço contratado em prejuízo da Administração Pública a reprimenda penal por chegar a 12 (doze) anos de reclusão.

Assim, dá-se justa punição para a fraude em licitação e contratos públicos, equiparando suas penas às mais elevadas sanções previstas nos crimes contra a Administração Pública no Código Penal.

Um novo delito é inserido pelo projeto de lei. Trata-se da omissão grave de dado ou de informação por projetista, prevista no art.337-O.

Novidades também aparecem nas disposições gerais sobre essas tipificações penais. Passa-se a prever expressamente que, ainda que tentados, tais delitos podem gerar como efeito da condenação penal de servidores públicos a perda do cargo, emprego, função ou cargo eletivo.

As penas bastantes elevadas e algumas expressões com significado aberto tais como "qualquer outro expediente" estão entre os questionamentos levantados pelos deputados federais para propor algumas das muitas emendas que já recebeu o projeto 
de lei, gerando impasse na sua votação e estendendo ainda mais seu tempo de tramitação.

\section{4 - Críticas}

Primeiramente, insta salientar que não existe real incentivo às denúncias contra irregularidades observadas no procedimento licitatório e nas contratações públicas. Apesar de a redação do projeto de lei atribuir legitimidade a todas as pessoas para apresentarem ao responsável o comportamento desviante notado, essa dicção do PL parece mais uma letra morta.

Isso porque o PL não vai além, não avança para realmente incentivar que essas denúncias sejam feitas, prevendo a possibilidade de qualquer pessoa noticiar o desvio mas de maneira mais pragmática, como que apenas "para constar".

Tal previsão solta, revela-se ineficiente eis que, do modo como está escrito, o cidadão não terá nenhum interesse em ser denunciante, com medo das consequências e retaliações que pode vir a sofrer.

$O$ ideal seria que fossem oferecidas recompensas ao denunciante que deseja combater o comportamento corruptivo, alguma vantagem econômica ou não que potencializasse o desejo de defender o interesse público em detrimento do particular. Entretanto, esse ganho do denunciante não pode ser tal que incentive denúncias vazias, falsas, apenas pelo sabor da recompensa, já que, neste caso, sobrepor-se-ia o interesse particular e, por consequência, estaríamos nos aproximando da troca de favores que tanto se deseja enfrentar.

Considerando que, na prática, o que se percebe são denúncias baseadas exclusivamente em interesses dos licitantes concorrentes, outra medida importante que deveria ser prevista no PL é a penalização de denúncias que não sejam lastreadas em informações verdadeiras ou que, pelo menos, estejam apoiadas em um mínimo de solidez, tal como existe nos Estados Unidos.

Outro ponto que vem sendo muito criticado pelos doutrinadores e operadores do Direito, é a questão da fiscalização dos contratos.

$\mathrm{O} P \mathrm{PL}$ até avança em algumas coisas relativas à atividade de fiscalizar, mas foi bem tímido neste ponto, o que abre espaço para ações corruptivas e/ou inadequadas. 
Como exemplo, citemos o fato de o PL não especificar quais são as atribuições de um fiscal. Não há menção sequer a uma primeira informações do que se espera do desempenho deste profissional, do momento do procedimento em que deve ser designado, da forma de designação, de sua escolha ou perfil esperado.

Mister se faz que o legislador infraconstitucional deixe evidenciado ao menos uma lista base, apontando o mínimo de atividades que incumbem ao fiscal, de modo que, a depender do tipo de contrato, sejam adicionadas novas tarefas. E também é necessário que exista e seja pública a formalização da designação do profissional, pois o que observamos hodiernamente na prática é que muitos são os casos em que a pessoa sequer toma conhecimento de que está, formalmente, na condição de fiscal perante o órgão contratante. Isso quando não o descobrem apenas após vir à tona alguma irregularidade cometida em seu nome.

Portanto, o fiscal precisa não só ter perfil para ocupar o cargo, como também estar preparado do ponto de vista de seu conhecimento para acompanhamento da execução do contrato, para enfrentamento das dificuldades e das irregularidades com que vai se deparar. Ademais, sua vida pregressa deve ser investigada, porque é inerente à função do fiscal a exigência de um antecedente probo, liso, honesto, o que atualmente e pela leitura do novo PL não se exigido.

\section{BUSCA PELA EFICIÊNCIA}

O princípio da eficiência passou a ganhar especial relevância a partir da publicação da Emenda Constitucional nำ19, em 04 de junho de 1998, a qual incluiu expressamente referido mandado de otimização como princípio norteador da Administração Pública, no artigo 37 da Constituição Federal de 1988, juntando-se aos da legalidade, impessoalidade, moralidade e publicidade.

O vocábulo "eficiência" deriva do latim, "efficere", que significa "realizar", "levar a cabo". Hodiernamente, o termo é administrativamente atribuído a uma boa gestão, isto é, aquela capaz de, dispondo de recursos escassos, extrair a melhor forma possível de utilização, de modo a alcançar resultados positivos sob o ponto de vista do atendimento do interesse público. 
Insta ressaltar que nunca será possível justificar uma atuação administrativa eficiente fora dos mandamentos legais. Por mais eficiente que seja uma atividade, se contrariar o ordenamento jurídico vigente, deverá ser cessada e seus atos, anulados.

Dito de outro modo, quando se trata de serviços públicos, não basta que o Poder Público atue sobre o manto da legalidade, exige-se a melhor atuação do agente público, a que produza resultados positivos e satisfatórios às vicissitudes dos administrados.

Com sua inserção no texto constitucional, a eficiência passa a ser imperativa. $O$ cidadão passa, então, a ter direito de questionar a realização e a qualidade de obras públicas diretamente exercidas pelo Estado ou por empresas por ele contratadas, o que é capaz de tornar mais harmoniosa e satisfatória a relação entre Estado e administrado.

Especificamente no tocante às licitações e contratações públicas, desde a Emenda Constitucional №19/1998, a eficiência foi utilizada como justificativa para tentar se minimizar a burocracia do procedimento licitatório, mormente na redução de etapas e prazos, na imposição de um planejamento adequado para as contratações e no acompanhamento da execução destas, sempre tendo em vista um resultado ótimo que agregasse efetividade às ações administrativas.

Neste ponto, peçamos licença ao leitor para abrirmos um parêntese com o intuito de diferenciar eficiência de efetividade, uma vez que, apesar de intimamente interligadas, possuem conceitos distintos. A eficiência consubstancia-se na ideia de produzir corretamente, utilização os recursos da melhor maneira possível, de modo que o custo-benefício seja o ideal. Por sua vez, a efetividade é a colocação em prática desta ideia, ou seja, representa a capacidade de reduzir custos operacionais da atividade entregando o produto final da melhor maneira possível (JUSTEN FILHO, 2011, p.367).

Como havíamos dito nos itens anteriores, o ganho de eficiência é o segundo pilar em que se sustentam as mudanças propostas pelo PL. Este passa a ser, portanto, o foco do presente capítulo, destrinchando nos itens subsequentes as inovações do PL 1.292 que buscam impactar positivamente a eficiência das contratações públicas.

\subsection{Contrato de eficiência}


A partir de sua inclusão no texto constitucional, em 1998, a eficiência passou a ser utilizada nas licitações e contratações públicas para, como se viu, melhorar o procedimento destas. Uma dessas inovações na matéria está na criação de novos critérios de julgamento das propostas, de modo a valorizar a vida útil do objeto contratual, aproveitando-o quando eficiente, tal como se deu em relação ao critério do maior retorno econômico.

Este critério surgiu pela primeira vez na legislação brasileira na Lei no12.462/2011, a Lei do Regime de Contratação Diferenciado - RDC, conforme verificamos na redação de seu artigo 23. De forma assemelhada, a recente Lei das Estatais (Lei 13.303/16) estabeleceu o critério do maior retorno econômico no julgamento de suas propostas (artigo 54, §6).

Como se vê os denominados "contratos de eficiência", também conhecidos como contratos de risco, de performance ou de desempenho, têm por objeto prestação de serviços que incluam ou não a realização de obras e o fornecimento de bens, com o escopo de entregar ao contratante maior economicidade. Neste caso, o contratado tem a sua remuneração baseada na economia gerada para o contratante.

Trata-se de um instituto realmente interessante, totalmente apoiado no princípio da eficiência administrativa, e que também foi contemplado pelo PL 1.292/1995 como, dentre outros, um dos critérios para o julgamento de proposta.

Assim, o critério de julgamento de proposta pelo maior retorno econômico será utilizado exclusivamente em se tratando de contratos de eficiência, cujo objetivo é gerar a redução das despesas correntes, as quais, conforme a Lei 4.320/1964, consubstanciam-se nas despesas de custeio, destinadas à manutenção de serviços, tais como os gastos com pessoal, material de consumo, serviços de terceiros, obras de conservação, e nas transferências correntes.

Os contratos de eficiência são perfeitamente aplicáveis ao consumo de água e de energia elétrica, por exemplo. 
A remuneração da empresa contratada é direta e exclusivamente vinculada à economia gerada para a Administração Pública, de modo que o investimento aplicado pelo Poder Público na implantação do sistema de eficiência é recuperado com a própria redução de despesas atingida; há um equilíbrio entre a economia gerada e a remuneração da empresa. Assim, é possível que se estenda no tempo, para além do fim do contrato de eficiência, o pagamento da empresa, pois, do contrário, inviabilizaria o negócio e não haveria interessados em contratar com a Administração.

Caso a empresa contratada não alcance a economia esperada e prevista no instrumento contratual, pelas mesmas razões acima expostas, haverá desconto em sua remuneração. E, do mesmo modo, se a diferença entre a economia contratada e alcançada for maior do que a remuneração, o contratado deverá suplantar o excedente (PIRONTI, 2019, online). Neste último caso, tal como previsto no PL, é possível ainda a aplicação de uma sanção em razão do inadimplemento acaso prevista expressamente no contrato.

A previsão do contrato de eficiência e do critério de maior retorno econômico é de fato demasiado interessante na busca da eficiência administrativa, desde que seja bem aplicada, pois apta a garantir a sustentabilidade econômica da Administração Pública, tão cara aos entes políticos brasileiros hodiernamente.

\subsection{Planejamento e padronizações}

A Lei 8.666/1993, desde sua publicação, foi duramente criticada em razão de ser demasiado complexa e formal na previsão de seus procedimentos, não atendendo à dinâmica da máquina administrativa e à demanda rotineira das entidades e órgãos públicos (e privados que recebem recursos públicos, estando obrigados a licitar). Tanto é que algumas leis vieram logo na sequência para corrigir tais distorções, como foi o caso da Lei 8.883/1994.

Conhecedores de tais dificuldades, os legisladores infraconstitucionais trabalham o PL 1.292 desde 1995 para aperfeiçoar as engrenagens do sistema de contratações públicas, aprimoramento este que foi feito iniciando-se pela previsão dos princípios, 
dentre os quais foi incluído o do planejamento, etapa tão importante no procedimento licitatório mas que foi silenciada pela Lei 8.666/1993.

Na busca pela eficiência, o PL 1292/1995 tomou o planejamento como mandado de otimização, prevendo-o em seu artigo 5ำ como princípio a ser observado na licitação e contratação públicas.

Na Lei de Licitações vigente, nenhum de seus 126 (cento e vinte e seis) artigos contempla esta temática, sendo patentes as consequências nefastas que a falta de planejamento ocasiona, razão pela qual o planejamento previsto no PL torna-se muito importante e valorizado.

Para alcançar a eficiência a partir do planejamento, a redação do projeto impõe como dever aos entes e órgãos públicos a confecção de um plano que racionalize e confira maior transparência às compras públicas, é o que se denomina Plano Anual de Contratação (PAC), previsto no artigo 12.

O PAC consubstancia-se em um documento que congrega todas as contratações que aquela entidade ou órgão público pretendem realizar ou prorrogar no exercício financeiro subsequente. Depreende-se do parágrafo único do supramencionado artigo que a tal plano deve-se conferir publicidade no sítio eletrônico oficial, o que permite o acompanhamento de sua execução por todos, inclusive administrados, para correção de defeitos.

$\mathrm{Na}$ verdade o PL traz em seu bojo o PAC como aprimoramento a sistemas parecidos já implantados por meio de Instruções Normativas - IN e Acórdãos do Tribunal de Contas da União - TCU. Entretanto, em termos de legalidade, é a primeira vez que o PAC vem previsto expressamente em um texto que pretende ter força legal (CAMARÃO, 2019, online).

A IN n 1 do Ministério da Economia, de 04 de abril de 2019, que "dispõe sobre o processo de contratação de soluções de Tecnologia da Informação e Comunicação TIC pelos órgãos e entidades integrantes do Sistema de Administração dos Recursos de Tecnologia da Informação - SISP do Poder Executivo Federal", prevê o plano anual de contratações bens, serviços, obras e soluções de tecnologia da informação no âmbito da Administração Pública Federal. 
Tal instrução normativa ampliou-se a possibilidade de realização de compras conjuntas, propiciando economia em larga escala para a Administração Pública Federal. Ademais, esta vantagem também facilita a organização dos fornecedores, que já tendo conhecimento da quantidade de bens, produtos e serviços pretendidos, pode melhor se preparar para atender a demanda.

Importante salientar que, hodiernamente, não é raro percebermos que as unidades administrativas utilizem como projeção de gasto as demandas do exercício financeiro anterior, apenas reproduzindo-as para o novo exercício, o que vai de encontro à necessidade de boa gestão. Como chama a atenção a professora Tatiana Camarão, "não basta promover a repetição dos quantitativos dos exercícios anteriores, é necessário fazer uma análise crítica do consumo médio real da unidade administrativa, observando as propostas e estratégias de crescimento e diminuição de consumo" (CAMARÃO, 2019, online). Para uma gestão ótima, mister se faz prévio levantamento dos gastos para se ter noção da real demanda do órgão.

Outro instrumento precursor do tratamento do planejamento anual foi o Acórdão n²622/2015 do Tribunal de Contas da União - TCU. Com relatoria do Ministro Augusto Nardes, a principal questão nele tratada foi o levantamento da situação de governança e gestão das aquisições na Administração Pública Federal (Perfil Governança das Aquisições - Ciclo 2013).

Assim, em suma, o plano anual permite que o Poder Público planeje suas ações e as torne mais efetivas, deixando ser meras "folhas de papel". Tão importante quanto conferir eficiência e efetividade através do planejamento, é disponibilizar por meio da rede mundial de computadores as contratações e aquisições efetuadas pelas entidades e órgãos, uma vez que assegura maior transparência e controle social.

Portanto, é evidente que a exigência de uma fase de planejamento torna mais burocrático o procedimento licitatório, eis que se acrescenta etapa inexistente no atual sistema; no entanto, entendemos tratar-se de necessidade já que a sintonia entre o planejamento anual e o contrato implica efetivo ganho de eficiência daquele dispêndio econômico do Poder Público. 
Decorrência lógica do princípio do planejamento são a valorização do Sistema de Registro de Preço - SRP e a padronização de serviços, produtos e até editais, grandes apostas do PL 1.292/95.

Pelo artigo 15 da Lei 8.666/1993 evidencia-se a deficiência da atual Lei de Licitações no tocante à padronização das especificações. A expressão "quando for o caso" expressa no inciso I do caput do artigo demonstra que o legislador infraconstitucional não priorizou a uniformização dos itens a serem adquiridos e dos serviços a serem contratados.

Andou bem o PL 1.292/1995 quando apostou na criação de um catálogo eletrônico de padronização de compras, serviços e obras - art.19. A imperatividade de tal sistema informatizado é positiva no sentido que estabelece uma padronização de bens, produtos e serviços, facilitando a elaboração de requisições e permitindo a otimização das aquisições pelos órgãos e entidades públicos.

A padronização inclui os editais de licitação, que de acordo com o projeto devem passar a utilizar cláusulas uniformes a fim de inibir a construção de minutas direcionadas ao favorecimento de determinado particular. Evita que o administrador público insira especificações com o intuito único de atender pedidos para favorecer ou prejudicar certo licitante. Com isso, busca-se não só a eficiência das contratações pelo fato de a padronização ser o reflexo de contínua discussão sobre melhorias nas aquisições da Administração Pública, mas também a redução da corrupção, aproximando-se neste ponto de todo o exposto no capítulo anterior.

Por sua vez, o SRP nada mais é do que um procedimento especial de licitação capaz de viabilizar inúmeras contratações, simultâneas ou sucessivas, por um ou mais órgãos da Administração Pública, de itens corriqueiramente comprados por estes, mas sem definição da quantidade necessária a ser adquirida. $O$ objetivo do instituto é agilizar as contratações, já que a lista de produtos previamente licitados tem validade de um ano, prorrogável por igual período, bem como evitar a formação de estoques, que elevam os custos da operação.

Quanto este sistema, observa-se que não se trata de nenhuma novidade, pois, como visto no artigo supramencionado, já estava previsto desde a Lei 8.666/1993. A 
abordagem da temática nesta lei, no entanto, foi inicialmente tímida, eis que concentrava o mecanismo apenas para aquisição de produtos, nada falando sobre serviços. Decretos posteriores mudaram essa realidade estendendo o sistema também para a prestação de serviços.

O interessante do PL 1292/1995 neste ponto é que ele promove a valorização do SRP inserindo uma série de pequenas modificações para adaptá-lo à realidade atual enquanto estratégia para aumentar a eficiência das contratações públicas e tornar mais célere o procedimento. Todo o capítulo III do projeto, do artigo 78 ao artigo 82, é dedicado ao SRP, cujo inteiro teor não explanaremos aqui por entender desnecessário, eis que muitas são as partes que se repetem do atual sistema, sendo certo que nos referiremos a seguir apenas às novidades.

Seguindo a ideia dos decretos posteriores à Lei 8.666/1993, o PL inclui a prestação de serviços como objeto do SRP, assim como as obras e serviços de engenharia (aquelas que puderem ser padronizadas e frequentes), conforme artigo 78, $\S 5^{\circ}$, apesar de o Tribunal de Contas da União - TCU sempre ter se posicionado de maneira contrária em relação a estes últimos. Outra novidade é a obrigatoriedade de constar do edital de licitação que adote o referido sistema dentre as especificidades do objeto a quantidade máxima de cada item a ser adquirida, de modo a proteger o contratado e a evitar privilégio de uma empresa em detrimento de outra. Explicamos valendo-nos do exemplo de Juliano Heinen:

[...] imagine que a empresa " $X$ " vença um certame de modo lícito, e, por casualidade, é próxima do gestor público, contribuiu com sua campanha eleitoral etc. Ora, nesta situação hipotética, o gestor passa a demandar muito mais do que se estivéssemos diante de uma empresa comum. Queremos dizer com isto que eventual privilegiamento pode ser mais bem controlado. Também, esta providência evita perda de economia de escala, na medida em que se fixou balizas objetivas em relação à quantidade que se quer adquirir. E, ainda, evitase que uma sucessividade de adesões possa também gerar perda de economia de escala, ou seja, em não se tendo o quantitativo máximo a ser adquirido, poder-se-ia permitir uma série de novas aquisições, aumentando sensivelmente a demanda, mantendo-se o preço fixado originalmente - quando que se sabe que, em termos econômicos, em geral, quanto mais se adquire, menor tende a ser o custo do produto demandado (HEINEN, 2020, [s.p.]). 
Tudo o que foi dito também serve para a "quantidade mínima a ser cotada de unidades de bens ou, no caso de serviços, de unidades de medida", exigência do artigo 78, inciso II, do PL.

Em atenção ao princípio da competitividade, o inciso III do artigo supramencionado respeitou a particularidades de cada licitante permitindo a previsão de preços diferentes em caso de: a) o objeto ser realizado ou entregue em locais diferentes; b) em razão da forma e do local de acondicionamento; c) ser admitida cotação variável em razão do tamanho do lote; d) por outros motivos justificados no processo. Essa variação no edital por óbvio, precisa ser justificada pelo gestor da entidade/órgão licitante.

Na mesma linha de atenção à competitividade está o inciso IV do artigo 78 que prevê a possibilidade de o licitante oferecer ou não a proposta em quantitativo inferior ao máximo exposto no edital. A ideia é proteger as microempresas e empresas de pequeno porte, facilitando sua participação no certame eis que podem não lograr fornecer maiores quantidades.

Por sua vez, o inciso $\mathrm{V}$ trata dos critérios de julgamento de propostas, os tipos de licitação que podem ser usados no Sistema de Registro de Preços, que se limita ao de menor preço e de maior desconto, neste último caso tomando por base a tabela de preços praticada no mercado, real e atualizada. Tais critérios valem, inclusive, para serviços e bens de engenharia, ou execução de obras.

No inciso VI do artigo 78, permite-se a alteração de preços registrados. Neste ponto, entretanto, é passível de críticas dos operadores do direito e dos gestores dos órgãos licitantes, pois há que haver melhor regulamentação do tema. A redação do dispositivo normativo é demasiado sucinta não sendo possível identificar em que casos realmente admitir-se-á esta modificação.

Nota-se avanço legislativo também na dicção do inciso VII daquele dispositivo, que elenca como exigência de o edital dispor sobre "o registro de mais de um fornecedor ou prestador de serviço, desde que aceitem cotar o objeto com preço igual ao do licitante vencedor, assegurada a preferência de contratação de acordo com a ordem de classificação". Como se vê, diferentemente do sistema atual, que registra na 
lista de preços apenas o licitante vencedor, o PL prevê a possibilidade de se registrar mais de um fornecedor de bem e produtos ou prestador de serviço, sem estipular limites, desde que previsto expressamente no edital. Neste caso, todos os licitantes registrados devem concordar em vender seus produtos/serviços pelo preço ofertado pelo licitante vencedor, assegurada a classificação quando da contratação. Tal inciso também privilegia o princípio da competitividade e também a eficiência na contratação, pois diante do não fornecimento dos objetos pelo licitante vencedor, existem outros para, pelo mesmo preço, suprir o desabastecimento do Poder Público.

Para finalizar, outra novidade é que o SRP poderá ser utilizado para contratações diretas, isto é, nas hipóteses de dispensa e inexigibilidade de licitação, inclusive em caso de o órgão ser não participante da licitação - o doutrinariamente denominado "carona" - desde que comprove cumprimento dos requisitos para tanto. $\mathrm{O}$ "carona", que no ordenamento vigente só tem previsão em decretos regulamentares, ganha amparo legal. Com isso, o sistema é melhor explorado, pois acomoda demandas de outros órgãos, participantes ou não. Para tanto, o órgão que promove a licitação fica obrigado a informar aos demais sua intenção de registro de preço para que estes, querendo, participem do procedimento e apresentem suas demandas.

Todas essas novidades do PL estão aliadas às recomendações de transparência internacional, mormente as diretivas europeias que foram a base para a redação do referido projeto de lei. Embora, como se vê, existam não só avanços, mas também críticas, no balanço final as regras de planejamento e padronização das contratações são interessantíssimas e representam, de fato, a pretensão de melhoria da eficiência neste campo.

\section{3 - Nova modalidade licitatória e a inversão de fases no procedimento}

Para celebração de contratos mais complexos, o PL 1292/95 incorpora na Nova Lei de Licitações uma nova modalidade: o diálogo competitivo, também conhecido como diálogo concorrencial. 
Trata-se de uma das mais principais e mais comentadas inovações do projeto, em grande parte porque não existe no atual ordenamento jurídico. A Lei 8.666/1993 prevê como modalidades de licitação: concorrência, tomada de preço, convite, leilão e concurso, sendo as três primeiras diferenciadas basicamente pelo critério do valor estimado do objeto do contrato, conforme artigo 23 do referido diploma com valores devidamente atualizados pelo Decreto nำ.412/2018.

As demais modalidades, leilão e concurso, não utilizam o valor do objeto como critério para sua definição, sendo assim conceituados: i) Leilão é a modalidade de licitação entre quaisquer interessados para a venda de bens móveis inservíveis para a administração ou de produtos legalmente apreendidos ou penhorados, ou para a alienação de bens imóveis prevista no art. 19, a quem oferecer o maior lance, igual ou superior ao valor da avaliação (art.22, §5ํㅡㄹ da Lei 8.666/93); ii) Concurso é a modalidade de licitação entre quaisquer interessados para escolha de trabalho técnico, científico ou artístico, mediante a instituição de prêmios ou remuneração aos vencedores, conforme critérios constantes de edital publicado na imprensa oficial com antecedência mínima de 45 (quarenta e cinco) dias (art.22, § $4^{\circ}$, daquela Lei).

Em 2002, surgiu uma nova modalidade de licitação denominada pregão que se destina à aquisição de bens e serviços comuns, qualquer que seja o valor. Previsto na Lei 10.520/2002, o pregão trouxe como novidade a inversão de fases, de modo que a habilitação do licitante vencedor faz-se apenas depois de abertas e classificadas as propostas, bem como a fase de adjudicação do objeto ao vencedor dá-se antes da homologação pela chefia do órgão licitante, diferentemente do que ocorre na Lei 8.666/1993.

O PL 1292 incorpora como regra para todas as modalidades de licitação, tomando por base a boa experiência do pregão, a inversão de fases. Dessa forma, primeiro se julgará as propostas apresentadas pelos concorrentes observando os critérios definidos no edital, e apenas depois da classificação passa-se a verificar os documentos de habilitação do licitante vencedor.

Nesses dezoito anos desde a publicação da Lei 10.520/2002, em razão da celeridade do procedimento e ampliação dos licitantes por meio do pregão eletrônico, 
privilegiando a eficiência e a competitividade do certame, o pregão se tornou a modalidade mais utilizada pela Administração Pública de todos os entes federativos brasileiros. Não é à toa, portanto, que algumas de suas inovações positivas foram aproveitadas pelo projeto de lei em andamento, tal como ocorreu com as positivas vantagens advindas da Lei do RDC (Lei oㅜ 12.462/2011).

Deste dispositivo se depreende também que o pregão e a concorrência são diferenciados em razão dos "padrões de desempenho e qualidade que possam ser objetivamente definidos pelo edital, por meio de especificações usuais de mercado". Assim, será utilizado o pregão se esses padrões forem os usualmente praticados no mercado; caso contrário, a modalidade será a concorrência. Note-se que não há qualquer referência ao preço estimado do objeto para diferenciá-los, critério extinto pelo projeto.

Em relação à modalidade concurso, o PL incorporou o entendimento doutrinário e jurisprudencial de que o licitante vencedor cede à Administração Pública todos os direitos patrimoniais relativos ao projeto e autoriza sua execução conforme ditames de conveniência e oportunidade, pelo que se permite ao Poder Público realizar alterações no projeto à sua livre discricionariedade, observados os princípios administrativos (vide artigos 29 e 91 ).

Quanto ao leilão, também houve inserção de novidades. Em contrariedade ao que se previa na Lei 8.666/1993, "o leilão pode ser cometido a leiloeiro oficial ou a servidor designado pela autoridade competente da Administração, devendo regulamento dispor sobre seus procedimentos operacionais", ex vi do artigo 30 do PL. Outra inovação deste projeto em relação ao leilão é o modo como se seleciona o leiloeiro oficial, o que passa a ser feito através de licitação na modalidade pregão e o critério de julgamento quanto às comissões é o de maior desconto, privilegiando os princípios da economicidade e eficiência.

Vê-se que foram retiradas as modalidades de tomada de preço e convite, bem como que uma nova modalidade foi inserida.

Importado do direito europeu, onde ele se consagra com reconhecido êxito nas contratações públicas, o legislador brasileiro passa a prever no PL o chamado diálogo 
competitivo, na linha da administração consensual, sendo definido pelo artigo $6^{\circ}$, inciso XLII, como a "modalidade de licitação para contratação de obras, serviços e compras de grande vulto em que a Administração Pública realiza diálogos com licitantes previamente selecionados mediante critérios objetivos com o intuito de desenvolver uma ou mais alternativas capazes de atender às suas necessidades, devendo os licitantes apresentar proposta final após o encerramento do diálogo".

Isto é, o diálogo competitivo destina-se às contratações complexas da Administração Pública tendo como instrumento o diálogo com a iniciativa privada. Funciona assim: a entidade ou órgão público que deseja licitar define suas necessidades e os critérios que serão utilizados para previamente selecionar os concorrentes. Os selecionados, então, participam de sessões com o objetivo de promover trocas de informações e apresentar soluções para os problemas relativos ao complexo objeto da licitação. Findo o diálogo com a definição da solução mais adequada, os licitantes apresentam suas propostas.

Em seu artigo 31, o PL restringe a utilização do diálogo competitivo para apenas algumas contratações, quais sejam, quando o objeto seja relativo à inovação tecnológica ou técnica; quando o órgão ou entidade não possa ter sua necessidade satisfeita sem a adaptação de soluções disponíveis no mercado; e se especificações técnicas não puderem ser definidas com precisão suficiente pela Administração.

Basta a leitura deste dispositivo para percebermos que as modalidades do pregão e da concorrência são totalmente diferenciadas do diálogo competitivo, tanto em relação ao procedimento como quanto ao objeto a ser licitado, não havendo qualquer traço de aproximação entre os três, a não ser pelo fim último de buscar a seleção da proposta mais vantajosa para a Administração.

Fazendo um balanço dos pontos positivos do diálogo competitivo no direito comparado, Thiago Marrara concluiu:

Das inúmeras modalidades licitatórias previstas na Diretiva Europeia 2014/24 para aquisição estatal de obras, serviços e bens, merece redobrada atenção o 'diálogo concorrencial', nome constante da versão oficial portuguesa da normativa, mas que, no Brasil, transformou-se em 'diálogo competitivo'... Por trás desta opção legislativa figura inicialmente a constatação de que 
procedimentos marcados pelo diálogo lograram mais sucesso na promoção do comércio transfronteiriço, ou seja, mostraram-se mais aptos a promover a competição efetiva entre agentes econômicos dos mais diversos países membros da União... a grande vantagem do diálogo concorrencial reside na possibilidade de se abrir a licitação ao mercado antes mesmo da definição da minuta contratual, fugindo-se da tradição de contratação por adesão que marca o direito administrativo (...) A modalidade em questão, em última instância, atribui à licitação muito mais que uma mera função de seleção do agente econômico que será contratado. Nela, a licitação assume uma função de aprendizado, de desenvolvimento e de inovação. Pelo diálogo, a licitação passa a gerar conhecimento, novos produtos e serviços em benefício do Estado, da efetividade de suas tarefas e do atendimento das necessidades coletivas (MARRARA, 2017, [s.p.]).

A administração consensual proposta pelo novo instituto é, portanto, muito bem sucedida no direito europeu, o que se espera que também ocorra no Brasil com os particulares interessados participando da definição das características necessárias ao objeto contratado bem como da estimativa do custo específico da contratação, influenciando previamente os valores que serão propostos pelos próprios licitantes, de modo que o equilíbrio econômico-financeiro do futuro contrato seja mais vantajoso ao Poder Público.

Com isso, alguns dos recorrentes problemas verificados nas contratações brasileiras tendem a acabar, tais como a contratação de objetos desatualizados em razão da ausência de estudos técnicos especializados acerca do objeto demandado pela Administração Pública. Não raro são as informações dos licitantes vencedores, após assinado o contrato, que o fabricante de determinado produto descontinuou sua produção especificamente ao que fora contratado, forçando alteração no que deverá ser entregue pelo vencedor, o que gera problemas de toda ordem.

Outro problema que terá fim consiste nas soluções individuais apresentadas pelos fornecedores como ideal para a solução do problema, mas que, na verdade, corresponde apenas as suas opiniões isoladas, sem respaldo em estudos e pesquisas, e que atendem aos seus próprios interesses em detrimento da necessidade pública.

Logo, inúmeras são as vantagens da nova modalidade licitatória. Entretanto, os seus principais desafios residem justamente na sua essência: as dificuldades de comparar apenas numericamente (ou objetivamente) propostas de soluções diversas 
para a necessidade pública, e de estimular a participação de licitantes, uma vez que destes será exigido o trabalho sem quaisquer garantias ou remuneração.

O sucesso do diálogo competitivo está, portanto, intrinsecamente ligado ao aumento da deferência às deliberações da Administração Pública no curso da licitação para que haja superação do atual ambiente de desconfiança e insegurança que pairam sobre as contratações públicas.

\subsection{Críticas}

Inobstante importantes e consistentes, as inovações do PL são muito tímidas, necessitando ser ampliadas em certos pontos e mais efetivas em outros.

Exemplo disso é a inversão entre as fases do julgamento/classificação e da habilitação, de modo que esta passa a ser posterior àquela, somente sendo habilitado o licitante vencedor após a classificação das propostas, entendemos que o ideal seria que o PL 1.292/1995 extinguisse a fase da habilitação do procedimento licitatório, postergando-a para o momento da contratação. Em outras palavras, o período de apresentação dos documentos pelo vencedor deveria ser posterior à homologação do resultado da licitação, uma vez que constituem requisito para a elaboração do contrato e não para finalizar o procedimento licitatório.

Quanto à inovação do diálogo competitivo, por certo é uma das novidades mais consistentes com regras minuciosas de seus requisitos e procedimento. Entretanto, para esta nova modalidade de licitação ser eficiente em muito contará com o empenho e a capacitação dos agentes públicos para a promoção de um diálogo engrandecedor entre os licitantes e de competitividade do certame, sob pena de ser infrutífero e beneficiar particulares em detrimento do interesse público.

\section{CONCLUSÃO}

Por tudo o que se expôs no presente trabalho, imperioso concluir que a consolidação das normas gerais de licitação em um único diploma agregando algumas 
boas experiências da legislação brasileira atual e do direito comparado por certo tem muito o que contribuir na melhoria das contratações públicas.

Dois pilares principais de sustentação das inovações do PL ํ⒈292/1995, o combate à corrupção e o enfrentamento à ineficiência das contratações públicas, foram contemplados com diversos dispositivos normativos e implementação de novos institutos para atendimento dos objetivos há tempos reivindicados pelos operadores do Direito, gestores públicos, bem como pelos próprios licitantes.

O principal problema da Lei $n^{\circ} 8.666 / 93$ foi enfrentado pelo projeto de lei: o planejamento. Terreno fértil para a prática de atos ilícitos no ordenamento jurídico vigente, a falta de uma fase específica para planejar a licitação de bens, objetos e serviços ficou sepultada de vez com a previsão minudenciada desta etapa no PL.

Apesar das críticas apontadas nos tópicos anteriores, inclusive quanto à morosidade ocasionada pela inclusão de nova fase, concluímos que o procedimento licitatório passa a ser melhor aproveitado para efetivar o principal objetivo da licitação: selecionar a proposta mais vantajosa para a Administração Pública, reduzindo os prejuízos advindos da ausência de planejamento.

Atento aos eficientes institutos de normas administrativas brasileiras e do direito comparado, o projeto acrescentou nova modalidade licitatória, o diálogo competitivo, além de exigências de implementação de programas de integridade e compliance. $\mathrm{Na}$ mesma toada, inseriu-se o festejado contrato de eficiência, que, como apontou Rodrigo Pironti (PIRONTI, 2019, online), rende bons frutos no direito pátrio após sua previsão na Lei das Estatais.

Ademais, outras inovações importantes foram a maior objetividade conferida às sanções administrativas bem como a reforma nos tipos penais ligados à licitação e aos contratos administrativos.

Todas essas novidades contribuíram, sem sombra de dúvidas, para o alcance dos objetivos-mor do projeto de lei, que eram conferir maior eficiência e exaltar estratégias de combate à corrupção em licitações e contratações públicas.

Entretanto, não avançamos em alguns aspectos importantíssimos tais como a extirpação da fase de habilitação do procedimento licitatório, que seria mais eficaz se 
postergada para o momento da contratação, de modo que foi apenas invertida de posição com a etapa da classificação de propostas, incorporando como regra a experiência positiva trazida pela Lei do Pregão (Lei 10.250/02).

Critica-se também a ausência de expressa previsão de procedimentos mais concretos de fiscalização da execução dos contratos ou ainda a falta de incentivo real a denúncias de comportamentos desviantes. Insta ressaltar que, a fim de assegurar maior equilíbrio econômico-financeiro nas contratações públicas, a redução significativa das prerrogativas públicas, mormente a possibilidade de rescisão unilateral pelo Poder Público, seria medida que conferiria maior atração de particulares ao procedimento licitatório e, consequentemente, minimizaria os custos para o órgão licitante.

Em suma, os embates ainda são inúmeros. É certo, contudo, que as medidas previstas no $P L$ no 1.292/1995 para uma administração estratégica efetiva e mais transparente dos órgãos e entidades públicas de fato são louváveis e merecem elogios, pois não só evitam a repetição de velhos erros como trazem à luz institutos bastantes positivos de outras normas brasileiras e alienígenas.

Resta esperarmos que o fato de ainda estar em tramitação o projeto da Nova Lei de Licitações seja utilizado como vantagem para a solução dos problemas restantes em grande parte apontados neste trabalho.

\section{REFERÊNCIAS}

AMORIM, Victor. Perspectivas de tramitação do projeto da nova Lei de Licitações em seu retorno ao Senado Federal. Observatório da Nova Lei de Licitações. Disponível em:< http://www.novaleilicitacao.com.br/2019/12/04/perspectivas-detramitacao-do-projeto-da-nova-lei-de-licitacoes-em-seu-retorno-ao-senado-federal/>>. Acesso em: 20 jan. 2020.

BITTENCOURT, Sidney. Licitação Passo a Passo. 10. ed. Belo Horizonte: Fórum, 2019.

BRASIL. Lei no 8.666, de 21 de junho de 1993. Regulamenta o art.37, inciso XXI, da Constituição Federal, institui normas para licitações e contratos da Administração Pública e dá outras providências. Disponível em: <http://www.planalto.gov.br/ccivil_03/leis//8666cons.htm>. Acesso em: 27 dez. 2019. 
. Ministério da Economia. Instrução Normativa no1, de 04 de abril de 2019. Dispõe sobre o processo de contratação de soluções de Tecnologia da Informação e Comunicação - TIC pelos órgãos e entidades integrantes do Sistema de Administração dos Recursos de Tecnologia da Informação - SISP do Poder Executivo Federal. Disponível em: <http://www.in.gov.br/materia//asset_publisher/Kujrw0TZC2Mb/content/id/70267659/do1-2019-04-05-instrucaonormativa-n-1-de-4-de-abril-de-2019-70267535>. Acesso em: 16 mar. 2020.

. Projeto de Lei no 1.292, de 1995. Estabelece normas gerais de licitação e contratação para as administrações públicas diretas, autárquicas e fundacionais da União, dos Estados, do Distrito Federal e dos Municípios; altera as Leis nos 13.105, de 16 de março de 2015 (Código de Processo Civil), 8.987, de 13 de fevereiro de 1995, e 11.079, de 30 de dezembro de 2004, e o Decreto-Lei oㅜ 2.848, de 7 de dezembro de 1940 (Código Penal); e revoga dispositivos da Lei no 12.462, de 4 de agosto de 2011, e as Leis nos 8.666, de 21 de junho de 1993, e 10.520, de 17 de julho de 2002. Disponível em: <http://www.novaleilicitacao.com.br/wp-content/uploads/2019/11/Projeto-Nova-Leide-Licitacao.pdf>. Acesso em: 27 dez. 2019.

CAMARÃO, Tatiana. O PL no $1292 / 95$ e a importância do planejamento das contratações. Observatório da Nova Lei de Licitações. Disponível em: < http://www.novaleilicitacao.com.br/2019/11/04/o-pl-no-1292-95-e-a-importancia-doplanejamento-das-contratacoes/>. Acesso em 19 mar. 2020.

FERNANDES, J. U. Jacoby. Lei no8.666/1993: Lei de Licitações e Contratos Administrativos e outras normas pertinentes. 20. ed. Belo Horizonte: Fórum, 2020.

HEINEN, Juliano. Controle das licitações e contratos públicos: linhas de defesa e atores. Observatório da Nova Lei de Licitações. Disponível em: <http://www.novaleilicitacao.com.br/2020/01/14/controle-das-licitacoes-e-contratospublicos-linhas-de-defesa-e-atores/\#_ftn1>. Acesso em: 05 mar. 2020.

Sistema de Registro de Preços na Nova Lei de Licitações. Observatório da Nova Lei de Licitações. Disponível em: <http://www.novaleilicitacao.com.br/2020/02/12/sistema-de-registro-de-precos-na-novalei-de-licitacoes/>. Acesso em: 22 mar. 2020.

JUSTEN FILHO, Marçal. Curso de Direito Administrativo. Belo Horizonte: Editora Fórum, $7^{\text {a }}$ ed. 2011.

MARINELA, Fernanda. Direito Administrativo. 6. ed. Niterói: Impetus, 2012.

MARRARA, Thiago. O "diálogo competitivo" como modalidade licitatória e seus impactos. Revista Consultor Jurídico. Disponível em: <https://www.conjur.com.br/2017jan-06/thiago-marrara-dialogo-competitivo-modalidade-licitatoria>. Acesso em: 25 mar. 2020. 
MEIRELLES, Hely Lopes. Direito Administrativo Brasileiro. São Paulo: Malheiros. 27. ed., 2002.

. Direito Administrativo Brasileiro. São Paulo: Malheiros. 24. ed., 1999.

MELO, Sidinei Pacheco de. Licitações e Contratos na Administração Pública. Rio de Janeiro: América Jurídica, 2000.

MENDES, Francisco Schertel; CARVALHO, Vinícius Marques. Compliance: concorrência e combate à corrupção. São Paulo: Trevisan, 2017. p. 11.

PIRONTI, Rodrigo. O princípio da eficiência e sua materialização pelo critério de julgamento do maior retorno econômico. Observatório da Nova Lei de Licitações. Disponível em: <http://www.novaleilicitacao.com.br/2019/10/30/o-principio-da-eficienciae-sua-materializacao-pelo-criterio-de-julgamento-do-maior-retorno-economico/>. Acesso em 14 mar. 2020.

ZILIOTTO, Mirela Miró A implementação de Programa de Integridade como condição de reabilitação de licitantes à luz do Artigo 162, parágrafo único, do Projeto de Lei no 1292/95. Observatório da Nova Lei de Licitações. Disponível em: < http://www.novaleilicitacao.com.br/2019/12/17/a-implementacao-de-programa-deintegridade-como-condicao-de-reabilitacao-de-licitantes-a-luz-do-artigo-162-paragrafounico-do-projeto-de-lei-no-1292-

95/?utm_source=portal_onll\&utm_medium=post\&utm_campaign=onll>. Acesso em: 02 fev. 2020 . 